\title{
Modeling and Evaluation for Effectiveness of Remote Sensing Satellite Based on ADC Model
}

\author{
Xinlin De, Jian Jiao* and Yipeng Zhu \\ School of Reliability and Systems Engineering, Beihang University, Bejing, China \\ ${ }^{*}$ Corresponding author
}

\begin{abstract}
With the development of space technology, remote sensing satellite is playing an increasingly important role in many fields. An effectiveness model of remote sensing satellite was proposed based on ADC model to provide a scientific basis for the design, development and actual use of remote sensing satellite. The possible states of the satellite are provided by analyzing the main mission and structure of the satellite. The state transition probabilities are calculated by continuous Markov chain with discrete states continuous time. Finally, a satellite effectiveness evaluation model is established based on ADC model. A case study is proposed to demonstrate the validity of the model.
\end{abstract} mission

Keywords-remote sensing satellite; effectiveness; ADC;

\section{INTRODUCTION}

Effectiveness is an important index of system, and has been studied in many industries [1-4]. The effectiveness of a system, in short, refers to the system's actual ability to complete an intended mission [5]. Accordingly, the definition of the effectiveness of remote sensing satellite can be summarized as its ability to carry out mission-specific remote sensing continuously within a designated area and a specified period of time, during which the collected information should meet a specific requirement. Modern remote sensing satellites have the characteristics of multi-function of structure, miniaturization and integration, so that the so the redundant design and the number of hardware are limited to a certain extent in volume, but the performance requirements of the entire satellite are not reduced relative to the traditional satellites .So, how to accomplish the mission efficiently with the existing resources has become a challenge we face. At present, there is not enough attention paid to the research on the effectiveness evaluation of remote sensing satellite. Although some domestic and foreign scholars [6-12] have studied the effectiveness evaluation of remote sensing satellite for specific functions, there is still a lack of research on the effectiveness evaluation of remote sensing satellite ,there is no doubt that effectiveness evaluation will be the focus of future research. On the other hand, effectiveness evaluation has been widely used in the fields of weaponry, machinery manufacturing and civil aviation. According to the characteristics of different industries, many methods to evaluate the effectiveness of the system have also been proposed. The introduction of effectiveness evaluation technology in remote sensing satellite system can reflect the ability of the system to a great extent.
This paper focused on the effectiveness evaluation of remote sensing satellite. In Section II, the characteristics of remote sensing satellite are analyzed; in Section III, an evaluation model of effectiveness is proposed based on ADC model combining with Markov model. A case study is given in Section IV, and some conclusions are summarized in Section V.

\section{Remote Sensing SATEllite Characteristics ANALYSIS}

With the increasing importance of space remote sensing technology in the national economy and defense fields, more and more attention has been paid to satellite remote sensing technology. Many new types of remote sensing satellites have been designed and the requirements for satellite missions are getting higher and higher. How to ensure remote sensing satellite to accomplish its mission effectively and efficiently and improve its effectiveness has become a major challenge for satellite designers. To evaluate effectiveness, a characteristics analysis of remote sensing satellite and its mission is needed.

Remote sensing satellite aims to observe various phenomena on the earth and can carry out uninterrupted remote sensing of designated areas within a specified time, including reconnaissance satellite, meteorological satellite and resource satellite [13]. Generally, a remote sensing satellite is composed of three parts, i.e. satellite platforms, remote sensors, equipment of information processing and transmission. Remote sensing satellite acquires various kinds of information about the earth and the atmosphere through remote sensors, preprocess the information through signal processing equipment and send the information back to the ground through transmission equipment. The following three points are required to accomplish a remote sensing mission:

\section{A. The Capability of High-speed Attitude Maneuver}

Attitude maneuver refers to the process of controlling the satellite's transition from one attitude to another [14]. This capability can make the satellite maintain its attitude stability when the satellite needs to change its remote sensor pointing quickly, so that it can observe the target quickly and efficiently. Compared with traditional attitude control, high-speed attitude maneuver can greatly improve the flexibility and observation efficiency of satellite, obtain the remote sensing information of the required target quickly and efficiently, so the capability of high-speed attitude maneuver is a development direction of the remote sensing satellite. 


\section{B. The Capability of High-resolution Imaging}

Remote sensing imaging is an integrated technology that uses electromagnetic wave theory and modern optics to collect and process electromagnetic signals radiated and reflected by long-range targets (not in contact with targets) through various sensing instruments [15]. Based on the capability of rotation attitude, the remote sensing satellite can realize remote sensing imaging. There are four types of main imaging modes in remote sensing satellite mission process:

- Multi angle imaging with full application of long synthetic aperture time

- Dynamic scanning and target detection for moving objects

- Single-orbit multi-mode continuous long-time imaging

- Multiple push-to-sweep splicing imaging in same orbit

\section{The Capability of Large Bandwidth Information \\ Transmission}

With the rapid development of earth observation technologies and remote sensing applications, the amount of raw data acquired at the same time is doubled, requiring higher rate or speed for information transmission, which make the contradiction between information and data transmission capacity more and more serious. Modern remote sensing satellite requires a capacity of transmitting and receiving information with large bandwidths, so that it can download data and receive commands from ground control stations and/or relay star quickly and accurately [16].

According to its mission characteristics, the structure of remote sensing satellite is simplified to facilitate the analysis in this paper. The satellite is divided into three subsystems, i.e. control and propulsion system $\left(N_{1}\right)$, imaging payloads system $\left(N_{2}\right)$, information transmission system $\left(N_{3}\right)$. These three subsystems do not affect each other as an independent event, and the logical structure of the satellite structure and functional mission is shown in Figure 1.

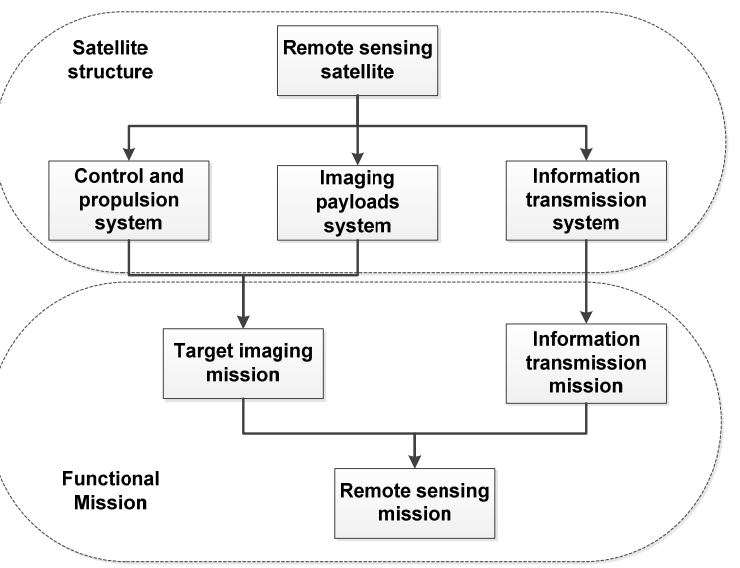

FIGURE I. THE LOGICAL STRUCTURE OF THE SATELLITE STRUCTURE AND FUNCTIONAL MISSION
From the simplified satellite structure shown in Figure 1, it can be seen that the control and propulsion system and the imaging payloads system jointly accomplish the remote sensing satellite target imaging mission, mainly including recognizing mission objectives, obtaining desired target information and preprocessing the information. Similarly, information transmission system aims to complete the information transmission mission, including downloading the obtained information to the ground observation station and receiving ground station control instructions. These two sub-missions are the main components of the satellite remote sensing mission, and they work together to complete the whole remote sensing mission, where the target imaging mission is the core mission for the entire remote sensing mission. In order to simplify the calculation, it is assumed that each subsystem only has two types of states, i.e. normal $(N)$ and fault $(\bar{N})$. Therefore, there are eight possible states during the remote sensing mission, as shown in Table 1:

TABLE I. THE STATES OF REMOTE SENSING SATELLITE

\begin{tabular}{|c|c|c|c|}
\hline $\begin{array}{c}\text { state } \\
\text { number } \\
(\mathbf{k}) \\
\end{array}$ & $\begin{array}{l}\text { system } \\
\text { state }\end{array}$ & State meaning & Mission situation \\
\hline 1 & $N_{1} N_{2} N_{3}$ & $\begin{array}{l}\text { All three subsys- } \\
\text { tems are in } \\
\text { normal conditionl }\end{array}$ & $\begin{array}{l}\text { The function is normal } \\
\text { and the remote sensing } \\
\text { mission can be completed }\end{array}$ \\
\hline 2 & $\overline{N_{1}} N_{2} N_{3}$ & $\begin{array}{l}\text { Control and } \\
\text { propulsion system } \\
\text { fault, the other } \\
\text { two sub-systems } \\
\text { are normal }\end{array}$ & $\begin{array}{l}\text { The information } \\
\text { transmission mission can } \\
\text { be completed but the } \\
\text { target imaging mission } \\
\text { and remote sensing } \\
\text { mission can not be } \\
\text { completed. }\end{array}$ \\
\hline 3 & $N_{1} \overline{N_{2}} N_{3}$ & $\begin{array}{l}\text { Imaging payloads } \\
\text { system fault, the } \\
\text { other two sub- } \\
\text { systems are } \\
\text { normal }\end{array}$ & $\begin{array}{l}\text { The information } \\
\text { transmission mission can } \\
\text { be completed but the } \\
\text { target imaging mission } \\
\text { and remote sensing } \\
\text { mission can not be } \\
\text { completed. }\end{array}$ \\
\hline 4 & $N_{1} N_{2} \overline{N_{3}}$ & $\begin{array}{l}\text { Information trans- } \\
\text { mission system } \\
\text { fault, the other } \\
\text { two subsystems } \\
\text { are normal }\end{array}$ & $\begin{array}{l}\text { The target imaging } \\
\text { mission can be completed } \\
\text { but the information } \\
\text { transmission mission and } \\
\text { remote sensing mission } \\
\text { can not be completed. }\end{array}$ \\
\hline 5 & $\overline{N_{1}} \overline{N_{2}} N_{3}$ & $\begin{array}{l}\text { Information trans- } \\
\text { mission system is } \\
\text { normal, the other } \\
\text { two subsystems } \\
\text { fault }\end{array}$ & $\begin{array}{l}\text { The information } \\
\text { transmission mission can } \\
\text { be completed but the } \\
\text { target imaging mission } \\
\text { and remote sensing } \\
\text { mission can not be } \\
\text { completed. }\end{array}$ \\
\hline 6 & $N_{1} \overline{N_{2}} \overline{N_{3}}$ & $\begin{array}{l}\text { Control and pro- } \\
\text { mote the system } \\
\text { is normal, the } \\
\text { other two } \\
\text { subsystems fault }\end{array}$ & $\begin{array}{l}\text { Loss of each function, all } \\
\text { missions can not be } \\
\text { completed }\end{array}$ \\
\hline 7 & $\overline{N_{1}} N_{2} \overline{N_{3}}$ & $\begin{array}{l}\text { Imaging payloads } \\
\text { system is normal, } \\
\text { the other two } \\
\text { subsystems fault }\end{array}$ & $\begin{array}{l}\text { Loss of each function, all } \\
\text { missions can not be } \\
\text { completed }\end{array}$ \\
\hline 8 & $\overline{N_{1}} \overline{N_{2}} \overline{N_{3}}$ & $\begin{array}{l}\text { Three subsystems } \\
\text { in the fault state, } \\
\text { the system fault }\end{array}$ & $\begin{array}{l}\text { Loss of each function, all } \\
\text { missions can not be } \\
\text { completed }\end{array}$ \\
\hline
\end{tabular}




\section{EFFECTIVENESS EVALUATION MODEL FOR REMOTE SENSING SATELLITE}

Proposed by Weapons System Effectiveness Industry Advisory Committee (WSEIAC) [17] in the middle of 1960s, The ADC model has been the classic effectiveness evaluation model, and it is the most widely applied effectiveness model by far. According to the model definition, system effectiveness is a measure of the degree to which a system is expected to meet a specific set of mission requirements and is the aggregate effectiveness of the three indicators of system availability, dependability and capability.

Similarly, the effectiveness of remote sensing satellite system is:

$$
E=A \cdot D \cdot C
$$

Where, A is the availability matrix, representing the probability of the system in different states when the remote sensing satellite begins its mission. D is the dependability matrix, the probability of transition between different system states during the mission under the condition that the remote sensing satellite has begun its mission. $\mathrm{C}$ is the capability matrix, representing the capability of remote sensing satellite to accomplish its mission under different states. The specific expression of A, D, C will discussed in following Sections.

\section{A. Availability of Remote Sensing Satellite}

The availability matrix $(A)$ of the remote sensing satellite is a row vector $\left(A_{1}, A_{2}, \ldots, A_{\mathrm{n}}\right)$. To get the availability matrix, the probabilities of different stats in the satellite need to be analyzed.

Using $a_{1}, a_{2}, a_{3}$ represent the probabilities of normal operation of the control and propulsion subsystem, imaging payloads subsystem and information transmission subsystem respectively. According to statistical results, the fault modes of satellite can be divided into two types, i.e. short-term fault and long-term fault. Short-term fault means that satellite can continue to be used after some maintenance measures controlled by ground control station, while long-term fault means that satellite cannot continue to be used, and need be replaced by the backup satellite. Because this paper focuses single remote sensing satellite, only short-term fault will be analyzed, and the mission is regarded as a failure if the satellite has a long-term fault. Let $M T B F_{1}, M T B F_{2}, M T B F_{3}$ represent the mean time between failures of the control and propulsion subsystem, imaging payloads subsystem and information transmission subsystem respectively, and $M T T R_{1}, M T T R_{2}$, $M T T R_{3}$ represent the average repair time of these three subsystems respectively, then the probability of normal operation of three subsystems is:

$$
\begin{aligned}
& a_{1}=M T B F_{1} /\left(M T B F_{1}+M T T R_{1}\right) \\
& a_{2}=M T B F_{2} /\left(M T B F_{2}+M T T R_{2}\right) \\
& a_{3}=M T B F_{3} /\left(M T B F_{3}+M T T R_{3}\right)
\end{aligned}
$$

In Table 1 there are eight types of states in remote sensing satellite. The probability that remote sensing satellite is in a certain state at the beginning of mission is the product of the state probabilities of three subsystems, for example, $A_{1}=a_{1} a_{2} a_{3}$. So, the system's availability matrix is:

$$
\begin{aligned}
& A=\left[a_{1} a_{2} a_{3},\left(1-a_{1}\right) a_{2} a_{3}, a_{1}\left(1-a_{2}\right) a_{3}, a_{1} a_{2}\left(1-a_{3}\right),\left(1-a_{1}\right)\left(1-a_{2}\right) a_{3},\right. \\
& \left.\left(1-a_{1}\right) a_{2}\left(1-a_{3}\right), a_{1}\left(1-a_{2}\right)\left(1-a_{3}\right),\left(1-a_{1}\right)\left(1-a_{2}\right)\left(1-a_{3}\right)\right]
\end{aligned}
$$

\section{B. Dependability of Remote Sensing Satellite}

The dependability matrix $(D)$ of the remote sensing satellite is a n-order-matrix, $\left[d_{\mathrm{ij}}\right]_{\mathrm{n} \times \mathrm{n}}$, where $d_{\mathrm{ij}}(\mathrm{i}, \mathrm{j}=1,2, \ldots, \mathrm{n})$ represent the probabilities of transitions between the different states during the mission, and $\mathrm{n}$ represents the number of states existing in the satellite. From Table 1, it can be seen that there are eight possible states in the satellite during the mission; moreover, the state changes can be expressed mathematically as a random process, $\{X(t), t \geq 0\}$, where $t$ is time. Because of the high quality and reliability, it is a reasonable hypothesis that two faults happen simultaneously in the satellite is a small probability event and the satellite state does not change within an operation time of $\Delta t(\Delta t \rightarrow 0)$ after a state transition. This assumption is also in line with the actual situation, and can greatly reduce the computational complexity. According to statistics, the reliability of satellite follows exponential distribution, therefore, assuming that the fault rates of the three subsystems are $\lambda_{1}, \lambda_{2}$ and $\lambda_{3}$ respectively, and the satellite is not repairable during space mission, i.e., the influence of maintenance is not considered. The state transition process of remote sensing satellite is shown in Figure 2:

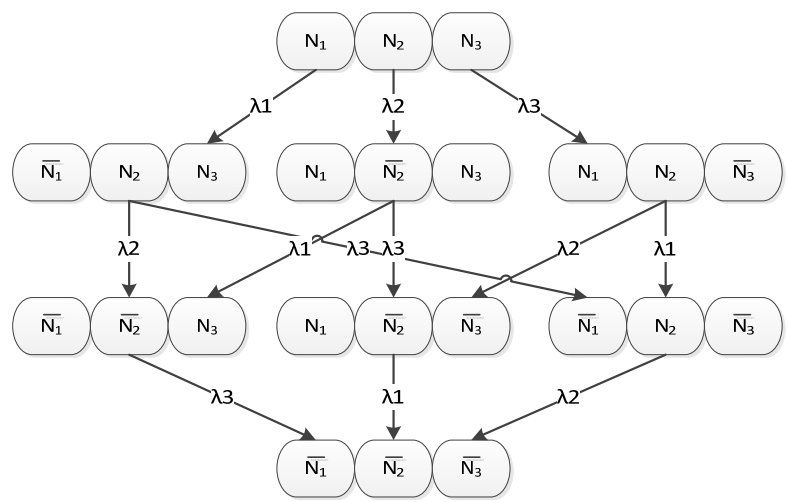

FIGURE II. STATE TRANSITION OF REMOTE SENSING SATELLITE SYSTEM

According to the state transition diagram of satellite system, the state transition process has the following characteristics: the probability of the system transferring from one state to another is only related to the present state. So the process can be transformed into Markov chains of continuous time. By using the mathematical expressions of Markov chains and fault rates of each subsystem, we can find out the transition intensities between the states. Based on the matrix form of Kolmogorov forward equation, the transition probability can be calculated, from which the dependability matrix $D$ is obtained. 

is:

The mathematical expression of continuous Markov chains

$$
P\{X(t+u)=j \mid X(u)=i\}=p_{i j}(u, t)
$$

It represents the probability that the system is in state $i$ at time $u$ and is transferred to state $j$ after time interval $t$. Because the reliability of system follows exponential distribution, the transition probability is independent of time $u$, and the Markov process is homogeneous, so

$$
p_{i j}(u, t)=p_{i j}(t)
$$

It is known from the previous assumptions that the satellite's state transition process cannot jump to another state immediately after entering a state, so the transition probability $p_{\mathrm{ij}}(t)$ satisfy regularity condition:

$$
\lim _{\mathrm{t} \rightarrow 0} p_{i j}(t)=\left\{\begin{array}{l}
1, i=j \\
0, i \neq j
\end{array}\right.
$$

And for any fixed $i, j \in I, p_{\mathrm{ij}}(t)$ is a consistent continuous function of $t$ and has the following limits:

$$
\left\{\begin{array}{c}
\lim _{\Delta t \rightarrow 0} \frac{p_{i j}(\Delta t)-1}{\Delta t}=q_{i j}, i=j \\
\lim _{\Delta t \rightarrow 0} \frac{p_{i j}(\Delta t)}{\Delta t}=q_{i j}, i \neq j
\end{array}\right.
$$

Where $q_{\mathrm{ij}}$ is called transfer intensity of a homogeneous Markov process. The transfer intensity of homogeneous Markov chains of continuous time can form a matrix shown below:

$$
Q=\left[\begin{array}{cccc}
q_{11} & q_{12} & \ldots & q_{1 n} \\
q_{21} & q_{22} & \ldots & q_{2 n} \\
\ldots & \ldots & q_{i j} & \ldots \\
q_{n 1} & q_{n 2} & \ldots & q_{n n}
\end{array}\right]
$$

From the matrix $Q$, An equation can be deduced to evaluate the transition probability for any time interval $t$, which can be expressed by the Kolmogorov forward equation:

$$
\frac{d p_{i j}(t)}{d t}=\sum_{k} p_{i k}(t) q_{k j}
$$

Where the initial conditions are:

$$
p_{i j}(0)=\left\{\begin{array}{l}
1, i=j \\
0, i \neq j
\end{array}\right.
$$

The matrix form of this equation can be written:

$$
\frac{d}{d t} P(t)=P(t) Q
$$

Where

$$
P(t)=\frac{d}{d t} P(t) Q^{-1}
$$

The transfer intensity matrix $Q$ can be obtained based on the fault rates of subsystems in the satellite, and then the state transition probability matrix $P(t)$ after a time interval $t$, that is the dependability matrix $D$, of the satellite can be calculated.

Because the distribution of subsystem fault follows an exponential distribution, we can get the transfer intensity matrix $\mathrm{Q}$ as follow:

$$
Q=\left[\begin{array}{cccccccc}
-\left(\lambda_{1}+\lambda_{2}+\lambda_{3}\right) & \lambda_{1} & \lambda_{2} & \lambda_{3} & 0 & 0 & 0 & 0 \\
0 & -\left(\lambda_{2}+\lambda_{3}\right) & 0 & 0 & \lambda_{2} & 0 & \lambda_{3} & 0 \\
0 & 0 & -\left(\lambda_{1}+\lambda_{3}\right) & 0 & \lambda_{1} & \lambda_{3} & 0 & 0 \\
0 & 0 & 0 & -\left(\lambda_{1}+\lambda_{2}\right) & 0 & \lambda_{2} & \lambda_{1} & 0 \\
0 & 0 & 0 & 0 & -\lambda_{3} & 0 & 0 & \lambda_{3} \\
0 & 0 & 0 & 0 & 0 & -\lambda_{1} & 0 & \lambda_{1} \\
0 & 0 & 0 & 0 & 0 & 0 & -\lambda_{2} & \lambda_{2} \\
0 & 0 & 0 & 0 & 0 & 0 & 0 & 0
\end{array}\right]
$$

The state transition probability matrix $P(t)$ can be calculated using formula (10). Due to the limitation of space, only the first line of the matrix is listed below:

$$
\begin{gathered}
D_{11}(t)=e^{-\left(\lambda_{1}+\lambda_{2}+\lambda_{3}\right) t}, D_{12}(t)=e^{-\left(\lambda_{2}+\lambda_{3}\right) t}-e^{-\left(\lambda_{1}+\lambda_{2}+\lambda_{3}\right) t}, \\
D_{13}(t)=e^{-\left(\lambda_{1}+\lambda_{3}\right) t}-e^{-\left(\lambda_{1}+\lambda_{2}+\lambda_{3}\right) t}, D_{14}(t)=e^{-\left(\lambda_{1}+\lambda_{2}\right) t}-e^{-\left(\lambda_{1}+\lambda_{2}+\lambda_{3}\right) t} \\
D_{15}(t)=e^{-\lambda_{3} t}-e^{-\left(\lambda_{1}+\lambda_{3}\right) t}-e^{-\left(\lambda_{2}+\lambda_{3}\right) t}+e^{-\left(\lambda_{1}+\lambda_{2}+\lambda_{3}\right) t}, \\
D_{16}(t)=e^{-\lambda_{1} t}-e^{-\left(\lambda_{1}+\lambda_{3}\right) t}-e^{-\left(\lambda_{1}+\lambda_{2}\right) t}+e^{-\left(\lambda_{1}+\lambda_{2}+\lambda_{3}\right) t}, \\
D_{17}(t)=e^{-\lambda_{2} t}-e^{-\left(\lambda_{2}+\lambda_{3}\right) t}-e^{-\left(\lambda_{1}+\lambda_{2}\right) t}+e^{-\left(\lambda_{1}+\lambda_{2}+\lambda_{3}\right) t}, \\
D_{18}(t)=1-e^{-\lambda_{1} t}-e^{-\lambda_{2} t}-e^{-\lambda_{3} t}+e^{-\left(\lambda_{1}+\lambda_{3}\right) t}+e^{-\left(\lambda_{1}+\lambda_{2}\right) t}+e^{-\left(\lambda_{2}+\lambda_{3}\right) t}-e^{-\left(\lambda_{1}+\lambda_{2}+\lambda_{3}\right) t}
\end{gathered}
$$

\section{Capability of Remote Sensing Satellite}

The capability matrix $C$ of remote sensing satellite is a measure of the degree to which the satellite performs its mission under different states. According to the mission composition of remote sensing satellite and the division of system states, the capability measures of the system in different states are classified into four categories, namely I, II, III and IV, and the corresponding value $B_{1}, B_{2}, B_{3}$, and $B_{4}$ can also be determined. Among them, the capability measure of the state that the function is normal and the remote sensing mission can be completed is class I. The capability measure of the state that 
the mission of target imaging can be finished but the information transmission and remote sensing mission cannot be completed is class II. The capability measure of the state that the mission of information transmission is normal but the target imaging and remote sensing mission cannot be completed is class III. The capability measure is class IV if none of the mission can be finished. Because there are eight states in remote sensing satellite, the capability matrix $C$ is:

$$
C^{T}=\left[\begin{array}{llllllll}
B_{1} & B_{3} & B_{3} & B_{2} & B_{3} & B_{4} & B_{4} & B_{4}
\end{array}\right]
$$

\section{A CASE STUdy}

\section{A. The Calculation of Availability Matrix A}

In a type of remote sensing satellite, the MTBFs and MTTRs of each subsystem are shown in Table 2:

TABLE II. PARAMETERS OF EACH SUBSYSTEMS OF REMOTE SENSING SATELLITE

\begin{tabular}{|c|c|c|c|}
\hline Subsystem & $\begin{array}{c}\text { Control and } \\
\text { propulsion } \\
\text { system }\end{array}$ & $\begin{array}{c}\text { Imaging } \\
\text { payloads } \\
\text { system }\end{array}$ & $\begin{array}{c}\text { Information } \\
\text { transmission } \\
\text { system }\end{array}$ \\
\hline $\mathrm{MTBF} / \mathrm{h}$ & 8600 & 12720 & 8784 \\
\hline $\mathrm{MTTR} / \mathrm{h}$ & 50 & 40 & 48 \\
\hline
\end{tabular}

According to the formula (2) and the data given in Table 2, the availabilities of three subsystems in remote sensing satellite are:

$$
a_{1}=0.9942, a_{2}=0.9969, a_{3}=0.9946
$$

And the availability matrix of the satellite can be obtained:

$\mathrm{A}=[0.9858,0.0058,0.0031,0.0054,1.7883 \mathrm{e}-05,3.1223 \mathrm{e}-$ $05,1.6643 \mathrm{e}-05,0]$

\section{B. The Calculation of Dependability Matrix D}

According to statistics, the fault of the satellite obeys exponential distribution, so the fault rates of the three subsystems can be calculated based the data in Table 2:

$$
\lambda_{1}=1.1628 \mathrm{e}-04, \lambda_{2}=7.8616 \mathrm{e}-05, \lambda_{3}=1.1384 \mathrm{e}-04 .
$$

And the transfer intensity matrix $\mathrm{Q}$ is:

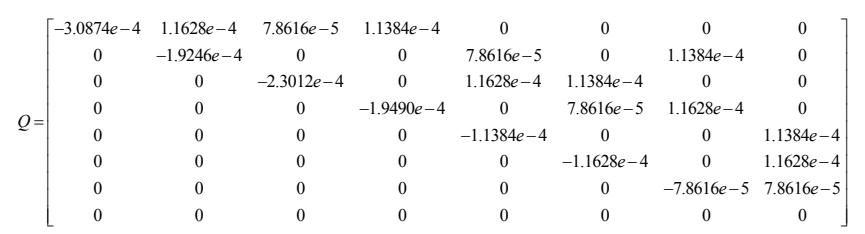

The mission time of this satellite is about $100 \mathrm{~h}$, so the dependability matrix $D$ is:

$$
D=\left[\begin{array}{cccccccc}
0.9696 & 0.0113 & 0.0077 & 0.0111 & 8.9504 e-5 & 8.7615 e-5 & 1.2984 e-4 & 0 \\
0 & 0.9809 & 0 & 0 & 0.0077 & 0 & 0.0112 & 0 \\
0 & 0 & 0.9773 & 0 & 0.0114 & 0.0112 & 0 & 0 \\
0 & 0 & 0 & 0.9807 & 0 & 0.0077 & 0.0115 & 0 \\
0 & 0 & 0 & 0 & 0.9887 & 0 & 0 & 0.0113 \\
0 & 0 & 0 & 0 & 0 & 0.9884 & 0 & 0.0116 \\
0 & 0 & 0 & 0 & 0 & 0 & 0.9922 & 0.0078 \\
0 & 0 & 0 & 0 & 0 & 0 & 0 & 1
\end{array}\right]
$$

\section{The Calculation of Capability Matrix $C$}

In this case, we defined that the range of capability values is between $0-10$, and the higher the value, the better the capability to complete the mission. The value of 0 means the satellite loss of function completely, and the value of 10 represents the satellite work well and can complete all the missions. So there four different state capability values:

$$
B_{1}=10, B_{2}=3.5, B_{3}=1.5, B_{4}=0
$$

The capability matrix $C$ is:

$$
C^{T}=\left[\begin{array}{llllllll}
10 & 1.5 & 1.5 & 3.5 & 1.5 & 0 & 0 & 0
\end{array}\right]
$$

As a result, the effectiveness of this satellite is:

$$
E=A \cdot D \cdot C=9.6566
$$

The example shows that, under the given conditions, the effectiveness of a remote sensing satellite is 9.6566 , while the ideal effectiveness is 10 .

\section{CONCLUSION}

Based on the mission characteristics and system structure, this paper established an effectiveness evaluation model of remote sensing satellite using ADC model. The possible states of the satellite, the probabilities under different states and the capability to accomplish the mission under different states are discussed. The model can supply a clear structure and simple way to assess the effectiveness of remote sensing satellite. It can be concluded that the satellite has the ability to complete the missions very well. Through the effectiveness evaluation model proposed in this paper, the concept of effectiveness is transformed into a parameter that can be measured quantitatively, and this method can provide a scientific decision basis for the design, development and actual use of remote sensing satellite.

On the other hand, the model is simple relatively because the satellite is divided only into three subsystems, and we will refine the model carefully according the system structure of satellite in the follow-up work.

\section{REFERENCES}

[1] Guo W H, Shao X F. Detection Effectiveness of Ship-borne Radar under Interference Environment Based on ADC Model [J]. Command Control \& Simulation, 2014(3):47-49. 
[2] Zheng X Y, Yao J S. A Method to Evaluate the Effectiveness of a Radar Based on FAHP [J]. Modern Radar, 2002, 24(2):7-9.

[3] Zhang P, Li S G, Xiao N. Effectiveness Evaluation for Armored Ambulance Combat Capability Based on Index Method [J]. Journal of Ordnance Equipment Engineering, 2016, 37(11):171-175.

[4] Li Y, Liu W. Research on Efficiency Evaluation Model of Electric Power Information System [J]. Advanced Materials Research, 2014, 1044-1045:1446-1451.

[5] Guo Q S. Introduction to Equipment Effectiveness Evaluation [M]. National Defense Industry Press, 2005.

[6] Meng J LI Q. Effectiveness Evaluation of Reconnaissance Satellite Based on the ADC Model [J]. Computer Science, 2009, 36(6):41-43.

[7] Zhang Z Q, Guo J E, Wang P. An AHP-based Approach for Evaluating Mission Planning

[8] Qin P C. Effectiveness Evaluation for Remote Sensing Satellite Application System Based on AHP, ADC and Gray Theory[J]. Modeling and Simulation, 2017, 06(04): 218-227.

[9] Zan X H, Guo X S, Ma L. Effectiveness Evaluation of Aerological Sounding System Based on the Improved ADC Method [J]. Journal of Ordnance Equipment Engineering, 2016, 37(6):61-64.

[10] Luo C X, Han J T. Analysis and evaluation of national defense system effectiveness-Based on ADC model development[C]// International Conference on Management Science and Engineering. IEEE, 2013:282288.

[11] Jin X, Hong Y J, Zhang M L. An Effectiveness Calculation Method Using Markov Model [J]. Journal of Projectiles, Rockets, Missiles and Guidance, 2005, 25(s6):260-262.

[12] Pang Y, Yang F, Wu Y. Coverage Effectiveness Evaluation of Remote Sensing Satellite System Based on AHP-FCE [J].Geomatics Sciencels\&/Stechnology, 2015, 03(5):42-50.

[13] Zhang Y S. Application of high resolution remote sensing satellite [M]. Science Press, 2004.

[14] Tu S C. Satellite Attitude Dynamics and Control [M]. Chinese Aerospace Press, 2003.

[15] Cheng B. Remote Sensing Image Fusion and Application Research [D]. University of Science and Technology of China, 2009.

[16] Wang W Y, Mao W, He Y C. Analysis of Data Transmission Technology for Remote Sensing Satellite Terrestrial Link [J]. Internet of Things Technologies, 2017, 7(7):33-36.

[17] Stevens W F. Weapon System Effectiveness Industry Advisory Committee [J]. Systems Engineering, 1964 